\title{
BIOTECHNOLOGICAL STUDIES ON BANANA PLANT: \\ 2. MORPHOLOGICAL AND MOLECULAR \\ CHARACTERIZATION OF SOMACLONAL VARIANTS \\ GENERATED FROM CULTIVAR 'GRAND NAINE'
}

Abdellatif, K. F. ; A. E. Hegazy ; H. M. Aboshama ; H. A. Emara and A. A. El-Shahed

Plant Biotechnology Dept., Genetic Engineering and Biotechnology Inst., Minoufiya University, Egypt.

\begin{abstract}
In vitro mass propagation and characterization (morphological and molecular, RAPD) of banana (Musa spp.) cultivar 'Grand Naine' was carried out. Produced 40000 vitroplants were screened for somaclonal variations during acclimatization, nursery and open field stages. The total detected variants were grouped into 25 off-types (two of them were died) in addition to the normal plant Random Amplified Polymorphic DNA (RAPD) was carried out to study the differences among the normal cultivar 'Grand Naine' and its 23 variants using 17 arbitrary primers. Cluster analysis results revealed that 'winged petiole' and 'deformed lamina' were more related to the normal plant. However, 'Giant plant' and 'weak plant' related to each other and clustered with normal plant. According to principal coordinate analysis, most of the variants were aggregated nearly whereas 'variegated plant' was separated apart from the other variants. This may reflect the genetic difference between 'variegated plant' and the other variants. The obtained results from both molecular and morphological analyses were so far in contiguous with better resolution when using the PCOORDA analysis than cluster analysis.
\end{abstract}

Keywords: Somaclonal variation, RAPD marker, cluster analysis, PCOORDA.

\section{INTRODUCTION}

Banana (Musa spp.) is one of the most important member of the Musaceae family. Bananas are grown in 128 countries with a total cultivated area of 4.92 million hectares since the total world production of 97.38 Million metric tons. India ranked first all over the world in banana production, which produces 27 million metric tons (FAO, 2009). Plants which have been propagated by in vitro tissue culture techniques are known to exhibit a wide array of genetic and epigenetic variation which known as somaclonal variation (James et al., 2007). Although the causes of genetic instability are poorly understood, chromosome instability is believed to be one of the most common causes of tissue culture-induced variation (Roux et al., 2004).

Characterization of induced mutations and somaclonal variations between induced mutant 'GN60A' and its original variety 'Grand Naine' of genomic DNA using arbitrary primers was performed by Fernandez et al. (1996). In addition Pancholi, et al., (1996) stated that a Random Amplified Polymorphic DNA (RAPD) marker based protocol was developed to screen for somaclonal variation in bananas in tissue culture, using Cachaco Enano $(A A B)$, Yangambi $(A A A)$ and Pisang Awak (ABB) plants. They reported that 
$17 \%$ of the plants were found to be variants and the variation was genotypedependent. Also, They presented that variability increased with an increase in the copy number of genome A, but it decreased with an increase in the copy number of genome B. These results indicated that RAPD markers could be used to monitor the levels of somaclonal variation. In this respect,Rajamanickam and Rajmohan (2007) reported that, out of the 41decamer primers screened for banana RAPD analysis, 34 could produce amplification. Twenty-five primers showed high level of polymorphism and six of the most promising primers (OPA-01, OPA-03, OPA-13, OPB-04, OPB-10 and OPB-12 were used for RAPD analysis. Recently, Saifullah et al., (2011) reported that thirteen varieties of the cultivated banana, procured from INIBAP, Belgium, were screened using RAPD-DNA markers. Only three RAPD primers (among 20 tested) were chosen as producing polymorphic DNA bands differentiating the investigated cultivars. Based on those identity markers, the genetic fidelity between various subculture levels were determined.

AFLP markers were used in conjunction with morphological descriptors, isoezymes, agronomic traits and random amplified polymorphic DNA (RAPD) markers to characterize the Musa accessions in the gene bank. Microsatellite markers were also used to characterize banana genotypes (Lagoda et al., 1995 and Creste et al., 2003). Creste et al. (2003) reported that phenetic analysis of microsatellite marker based on Jaccard similarity index derived from presence or absence of the alleles agreed with the morphological classification.

The main objective of this study was to characterize the produced banana vitroplants for both morphological and molecular (RAPD) markers and to compare the results of both marker types.

\section{MATERIALS AND METHODS}

\section{Plant Material and Morphological Traits:}

Healthy and uniform banana offshoots of cultivar 'Grand Naine' were selected from a certified model farm in August 2008. The offshoots were proliferated at the Plant Tissue Culture Laboratory, Plant Biotechnology Dept., Genetic Engineering and Biotechnology Institute, , Minufiya University, Egypt. Twenty-five off types were produced throughout the proliferation and the evaluation of the produced vitroplants. The off types were considered as somaclonal variants (Hegazy et al. 2010). All produced banana somaclonal variants and normal vitroplants were grown in greenhouses and open field during the period from 2009 until 2011 in a model farm at Ahmed Oraby Village, Badr City, Beheira Governorate, Egypt in order to be evaluated.

Morphological identification was applied from the period after 6 weeks of acclimatization until the fruit stage. Screening of all vitroplants (40000) was achieved to identify the off-type plants and classified them according to their type. The morphological data were recorded during the nursery stage, in the field stage and the fruit stage (Table 1). 
Table 1: Economical evaluation of normal banana cultivar 'Grand Nain' and its off-types based on morphological traits (Hegazy et al., 2010).

\begin{tabular}{|c|c|c|c|c|c|c|}
\hline No. & Phenotype case & Acc. & Nursery & $\begin{array}{c}\text { Open } \\
\text { field }\end{array}$ & $\begin{array}{c}\text { Bunch } \\
\text { Weight (kg) }\end{array}$ & $\begin{array}{l}\text { Quality } \\
\text { degree }\end{array}$ \\
\hline 1 & Normal & + & & & 29.00 & 1 \\
\hline 2 & Spear shape lamina & + & & & 27.92 & 1 \\
\hline 3 & Leathery lamina & - & & & 4.89 & 3 \\
\hline 4 & Winged petiole & + & & & 28.44 & 1 \\
\hline 5 & Asymmetric lamina & + & & & 28.59 & 1 \\
\hline 6 & Lamina deformation & + & & & 28.72 & 1 \\
\hline 7 & Half variegated lamina & + & & & 27.61 & 1 \\
\hline 8 & Variegated plant & - & & & 16.14 & 2 \\
\hline 9 & Stripped lamina & + & & & 27.64 & 1 \\
\hline 10 & Malformed plant & - & & & 6.07 & 3 \\
\hline 11 & Fan shape plant & + & & & 27.68 & 1 \\
\hline 12 & Dwarf plant & + & & & 23.58 & 1 \\
\hline 13 & Sprocket lamina & & - & & 3.47 & 3 \\
\hline 14 & Default lamina & & + & & 16.24 & 2 \\
\hline 15 & Reddish lamina & & + & & 22.60 & 1 \\
\hline 16 & Long petiole & & + & & 22.90 & 1 \\
\hline 17 & Pale green pseudo stem & & + & & 24.89 & 1 \\
\hline 18 & Elephant ear shape & & - & & 10.63 & 2 \\
\hline 19 & Erected leaf & & - & & 9.63 & 3 \\
\hline 20 & Blackened pseudo stem & & & + & 18.46 & 1 \\
\hline 21 & Shattered punch & & & - & 9.88 & 3 \\
\hline 22 & Giant plant & & & + & 22.36 & 1 \\
\hline 23 & Vigor plant & & & + & 32.04 & 1 \\
\hline 24 & Weak plant & & & - & 11.24 & 2 \\
\hline
\end{tabular}

Quality degree: (1) > 18 kg, (2) 10 to 18 kg, (3) < 10 kg

(+) Could be planted, (-) Should be excluded

\section{DNA isolation:}

Fresh white cigar leaves of the 'Grand Naine' banana cultivar and its 23 off types, which were derived from the tissue culture propagation, were harvested and bulked, immersed in liquid nitrogen and stored at $-70{ }^{\circ} \mathrm{C}$ until DNA extraction. Total genomic DNA was isolated from the stored leaves using modified standard CTAB method (Saghai-Maroof et al., 1984) and then preserved at $-20^{\circ} \mathrm{C}$ until used.

Random Amplified Polymorphic DNA (RAPD) analysis:

RAPD-PCR was performed using 17 10-mer random primers selected from the Operon kit (Table 2). PCR reactions were carried out in $25 \mu$ volumes containing $75 \mathrm{ng}$ of template DNA, $1 \mathrm{X}$ reaction buffer, $1.5 \mathrm{mM}$ $\mathrm{MgCl}_{2}, 200 \mu \mathrm{M}$ dNTPs, $1.5 \mu \mathrm{M}$ of the primer and $1 \mathrm{U}$ of the Taq DNA polymerase (Promega). PCR amplification was performed for 35 cycles at $94^{\circ} \mathrm{C}$ for 1 minute, $30^{\circ} \mathrm{C}$ for 1 minute and $72^{\circ} \mathrm{C}$ for 1 minute. The program was preceded by a denaturation step at $94{ }^{\circ} \mathrm{C}$ for 7 minutes and followed by an elongation step at $72{ }^{\circ} \mathrm{C}$ for 7 minutes. The PCR products were separated on $1.5 \%$ ethidium bromide stained agarose gels and were photographed on gel documentation system. 


\section{Data analysis:}

Gels of the RAPD analysis were scored as $0 / 1$ for absence/presence of DNA bands, respectively. The total number of band and the number of polymorphic bands were calculated as well as the polymorphic information content (PIC) which was calculated according to Anderson et al. (1993) using the following simplified formula: $P I C_{i}=1-\Sigma p^{2}{ }_{i j}$

Where $p_{i j}$ is the frequency of the th allele for marker ith summed across all alleles for the locus. The morphological data were standardized and then the similarity matrix was calculated using the simple matching coefficient. Similarity matrix was calculated for the RAPD data using Jaccard coefficient (Jaccarad, 1908). Dendrograms were constructed for both morphological and RAPD data based on the UPGMA clustering method using NTSYSpc software version 2.0 (Applied Biostatistics, Setauket, New York, USA) (Rohlf, 1998).

Principal coordinate analysis (PCOORDA) was carried out for the standardized decentered morphological and RAPD data. Eigen values and Eigen vectors were calculated for the transformed interval data and the threedimensional PCOORDA plot was constructed using the NTSYSpc software.

\section{RESULTS AND DISCUSSION}

\section{Polymorphism and polymorphic information content (PIC):}

The total number of bands and the number of polymorphic bands of 'Grand Naine' banana cultivar and its variants were calculated for each RAPD primer as well as the polymorphic information content (PIC, Table 2). The 17 RAPD primers produced in total 129 bands, 109 from which were polymorphic ( $84.5 \%$ polymorphism, Table 2 ). The total number of bands for each primer ranged from two bands for the primer OPN-03 to 12 for the primer OPA-03 while the number of polymorphic bands ranged from one band for the primer OPN-03 to nine bands for the primers OPA-03, OPH-17 and OPN-09 (Table 2). The polymorphism percentage for the RAPD primers ranged from $50 \%$ for the primer OPN-03 to $100 \%$ for the primers OPA -13 , OPC-15, OPH-17, OPN-09 and OPR-02 (Table 2). The polymorphic information content (PIC) for RAPD primers was high in general and ranged from 0.50 for the primer OPN-03 to 0.89 for the primers OPB-12, OPH-17, OPM-16 and OPN-09 (Table 2). Thus, it seems that very high percentages of polymorphisms as well as PIC (82\% as average overall the primers) were generated from the RAPD primers used in this study. These results could support their use in characterization studies to differentiate the variants from the original parents. In contrast, Zaffari and Kerbauy ( 2010 ) stated that The Random Amplified Polymorphic DNA (RAPD) analysis was carried out using 20 primers, having only two of them (10\%) shown polymorphism among the 'dwarf' and 'variegated plants' in relation to the normal plants.

DNA fingerprinting is widely used to detect somaclonal variation and to assess the genetic identity and stability in banana vitroplants (Lu et al., 2011). From the present investigation, the random amplified polymorphic DNA (RAPD) technique has been used to detect the differences among 
'Grand Naine' banana cultivar and its variants. Similarity matrix of the normal 'Grand Naine' banana cultivar and its variants was calculated based on RAPD data using the Jaccard similarity coefficient to obtain the similarity correlation coefficient between each pair of the used genotypes (Table 3). The highest relationship was observed between the normal plant and 'winged leaf' type (0.84), as well as between 'deformed lamina' and 'winged petiole' $(0.84)$, followed by between 'spear shape lamina' and normal plant $(0.82)$ and then between 'deformed lamina' and normal plant $(0.82)$. In the contrary the lowest similarity was observed between 'blackened pseudo stem' and 'variegated plant' (0.40), 'pale green pseudo stem' and 'variegated plant' (0.41) and between 'giant plant' and 'variegated plant' $(0.42$, Table 3$)$. These results support the previous results using the morphological traits (Hegazy et al., 2010) which reported that both 'winged leaf' and 'deformed lamina' types were not differed from the 'Grand Nain' normal type.

Table 2: Total and polymorphic bands number and the polymorphic information content (PIC) generated by 17 RAPD primers from banana cultivar 'Grand Nain' and its somaclonal off-types.

\begin{tabular}{|l|l|c|c|c|c|}
\hline Primer & Sequence (5' - 3') & Total bands & Polymorphic bands & \% Polymorphism & PIC \\
\hline OPA-01 & CAGGCCCTTC & 8 & 7 & 87.5 & 0.88 \\
\hline OPA-03 & AGTCAGCCAC & 12 & 9 & 75 & 0.88 \\
\hline OPA-13 & CAGCACCCAC & 7 & 7 & 100 & 0.86 \\
\hline OPB-10 & CTGCTGGGAC & 9 & 7 & 77.8 & 0.84 \\
\hline OPB-12 & CCTTGACGCA & 9 & 8 & 88.9 & 0.89 \\
\hline OPC-07 & GTCCCGACGA & 5 & 4 & 80 & 0.80 \\
\hline OPC-15 & GACGGATCAG & 7 & 7 & 100 & 0.86 \\
\hline OPD-02 & GGACCCAACC & 9 & 7 & 77.8 & 0.84 \\
\hline OPE-15 & ACGCACAACC & 5 & 3 & 60 & 0.72 \\
\hline OPH-17 & CACTCTCCTC & 9 & 9 & 100 & 0.89 \\
\hline OPM-16 & GTAACCAGCC & 9 & 8 & 68.9 & 0.89 \\
\hline OPM-20 & AGGTCTTGGG & 5 & 3 & 50 & 0.72 \\
\hline OPN-03 & GGTACTCCCC & 2 & 1 & 100 & 0.50 \\
\hline OPN-09 & TGCCGGCTTG & 9 & 9 & 75 & 0.89 \\
\hline OPN-10 & ACAACTGGGG & 8 & 6 & 75 & 0.84 \\
\hline OPW-07 & CTGGACGTCA & 8 & 8 & 100 & 0.78 \\
\hline OPR-02 & CACAGCTGCC & 8 & & & \\
\hline
\end{tabular}

\section{Molecular Cluster analysis:}

According to cluster analysis of the RAPD data, the variants were clustered with different degrees of similarity in relation to the normal plant (Figure 1). The variants and their normal parent 'Grand Naine' banana cultivar were clustered into five clusters according to the cluster analysis (Figure 1). The first cluster included two subclusters; the first subcluster contained the normal plant (cultivar 'Grand Naine') and the variants 'winged petiole', 'deformed lamina', 'giant plant' and 'weak plant'. The variants 'winged petiole' and 'deformed lamina' were clustered together along with the normal plant (Figure 1). The second subcluster contained 'half variegated' lamina, 'vertical stripped' lamina and 'malformed' plant (Figure 1). The variant 'spear shape lamina' was separated in between the above mentioned two subclusters. 
Abdellatif, K. F. et al.

3

1598 
The second cluster included 'asymmetric lamina', 'fan shape plant' and 'shattered bunch' variants (Figure 1). The third cluster included the variants 'long petiole' and 'elephant ear shape lamina' (Figure 1). The fourth cluster included 'leathery lamina', 'dwarf plant', 'default lamina', 'blackened pseudo stem' and 'reddish lamina' variants. The fifth cluster included 'sprocket lamina' and 'vigor plant' variants, while the 'erected leaf' variant was separated in between the fourth and fifth cluster. Both 'pale green pseudo stem' and 'variegated plant' variants were clustered separately each apart of the above-mentioned clusters (Figure 1).

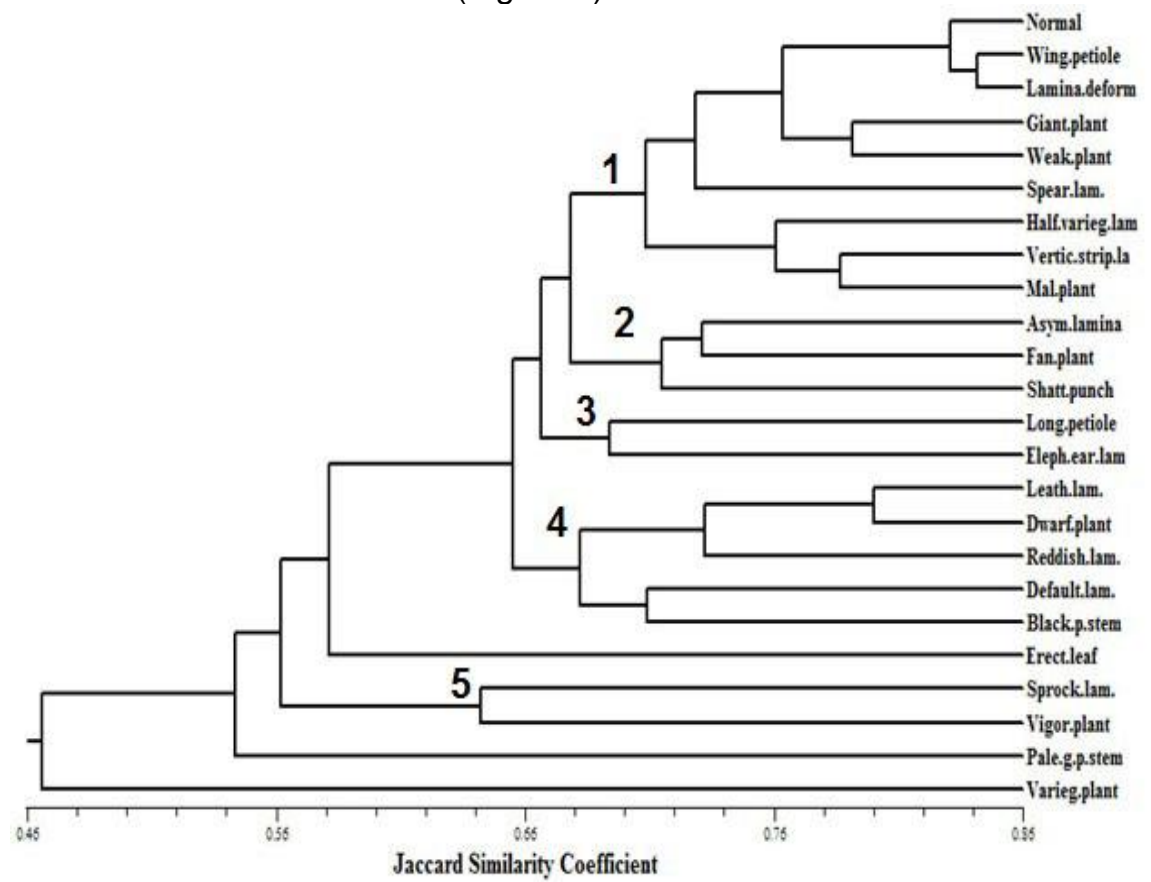

Figure (1): Cluster analysis of banana cultivar 'Grand Nain' and its twenty-three somaclones generated from RAPD data using Jaccard similarity coefficient and UPGMA clustering method.

These results were in agreement with those previously obtained by the screening along the different stages (Hegazy et al., 2010). Most of the somaclonal variants appeared related to each other according to the cluster analysis. Those variants showed the same trend in the vegetative and reproductive stages for example, the 'winged petiole' variant reverted in the subsequent stage and showed the same behavior as the normal plant, which exactly we can see in the previous cluster analysis. The same trend was observed with the 'deformed lamina' variant and many other somaclonal variants. 
Molecular Principle Coordinates Analysis (PCOORDA):

According to the principle coordinate analysis (PCOORDA) of the RAPD data, the first three principle coordinates (PCs) accounted for $41.4 \%$ of the total variation (18\% for PC1, $13.4 \%$ for PC2 and $9 \%$ for PC3, Figure 2 ) which reflect the reliability of the generated 3D graph of the PCOORDA analysis. The variants distributed on the base of the first PC (which represented the most variability in the analysis, ( Figure 2) in different degrees, whereas the 'variegated plant' variant separated apart from other variants at the most high level of the first PC. It may be indicated that the 'variegated plant' genetically different from other types, while it was aggregated with all variants based on the second PC.

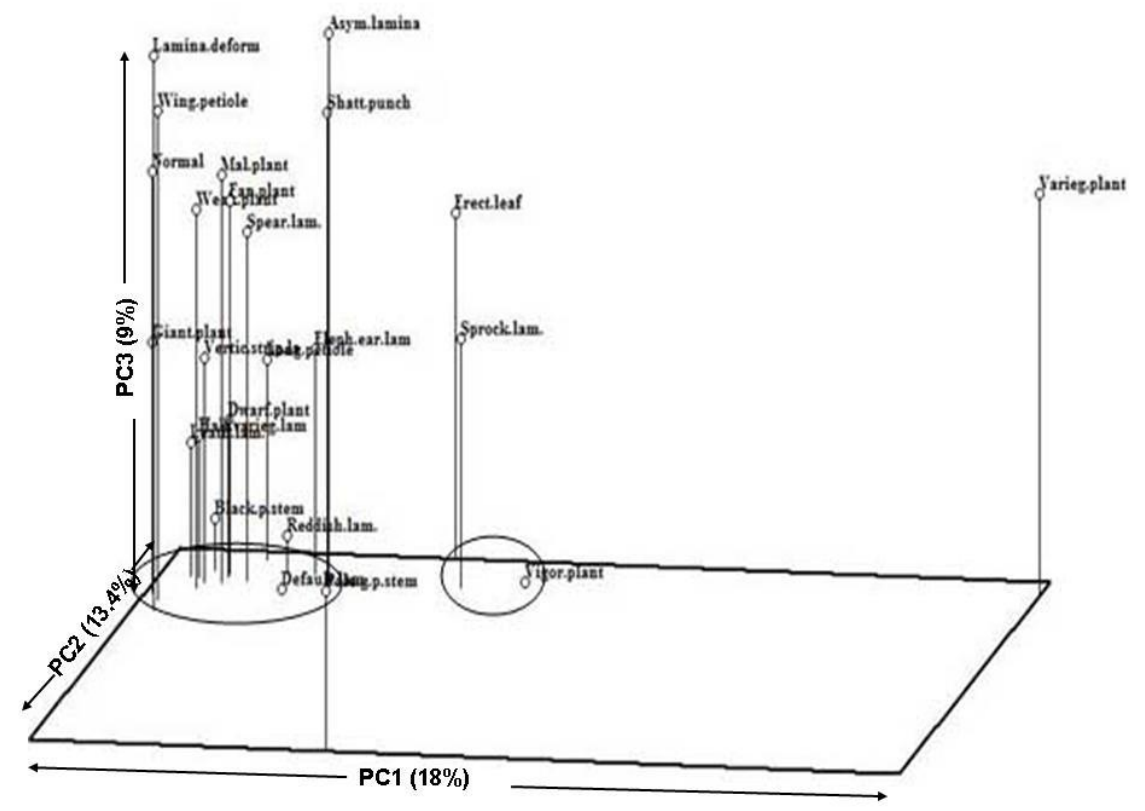

Figure (2): PCOORDA for banana cultivar 'Grand Nain' and twenty-three of its somaclonal

The following variants were aggregated near from the middle of PC1: 'vigor plant', 'sprocket lamina', 'erected leaf' and 'pale green pseudo stem' and were separated from all other variants which were aggregated along with the normal plant at low level of the first PC (Figure 2). At the second principal coordinate (PC2), there were no high differences among the variants in relation to their distribution at this level except for 'pale green pseudo stem' variant which was located at the lowest level of this PC (Figure 2). At the third PC, there were no high differences among the variants in relation to their distribution at this level except for 'vigor plant', 'default lamina' and 'reddish lamina', which were located at very low level of that PC (Figure 2). 
Data obtained by PCOORDA were in consistent with those previously obtained by vegetative and reproductive screening and previous cluster analysis. The 'variegated plant' appeared segregated alone at the edge of the PC1. The latest variant showed different agronomic characteristics from other variants, showed different pattern of DNA fragments, and appeared apart from other variants in the cluster analysis (Hegazy et al., 2010). That was exactly what we obtained from either growth stages or previous cluster analysis. The same thing can be noted about the 'erected leaf' and 'sprocket lamina' and other variants. They gave the same trend all over growth stages, fruiting stage and cluster analysis.

Morphological Cluster analysis:

According to cluster analysis of the morphological data, the variants were clustered with different degrees of similarity in relation to the normal plant (Figure 3).

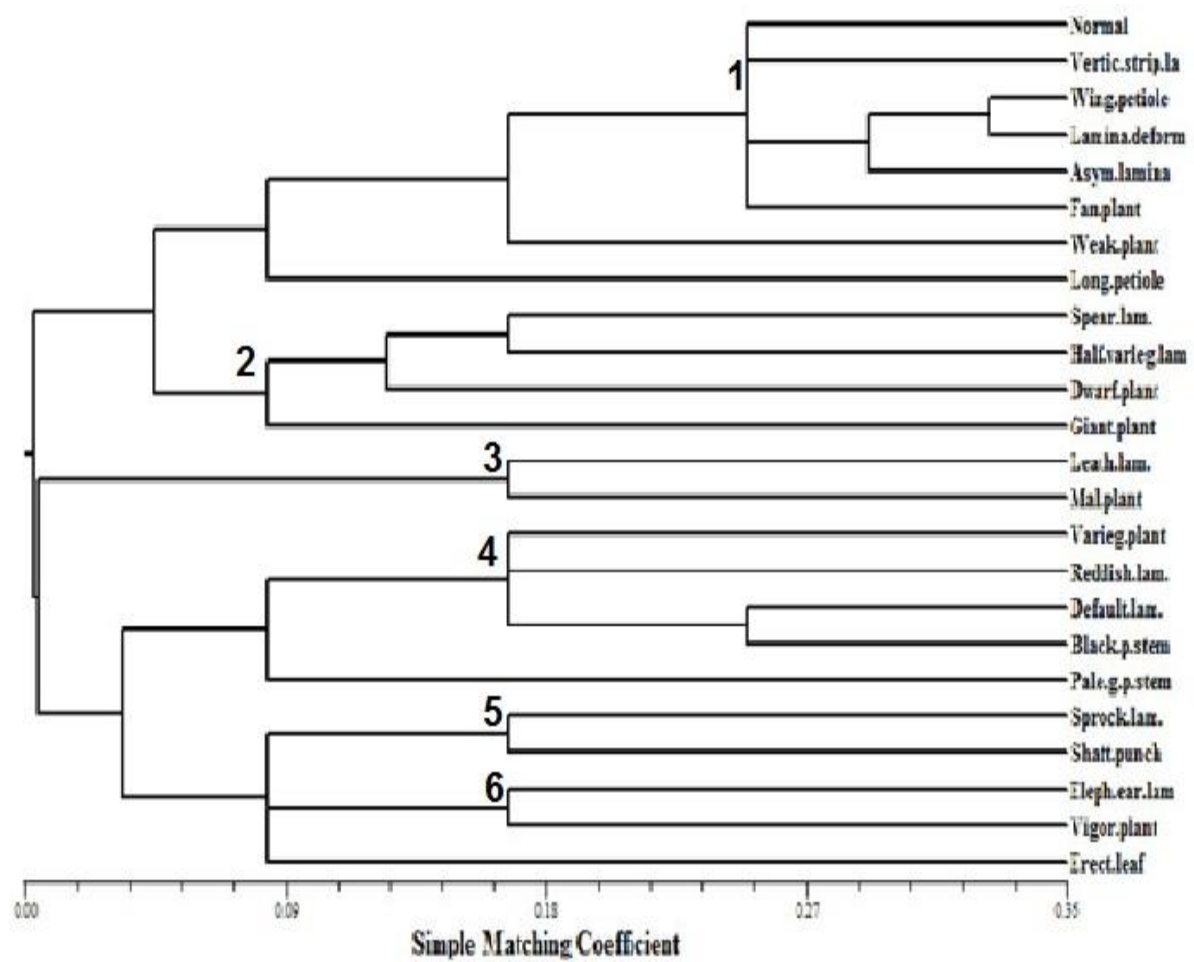

Figure (3): Cluster analysis of similarity tree for banana cultivar 'Grand Nain' and twenty-three of its somaclonal variants based on morphological parameters.

The variants and their normal parent plant ('Grand Naine' banana cultivar) were clustered into six clusters (Figure 3 ). The first cluster included the normal plant (cultivar 'Grand Naine') and the variants 'winged petiole', 'asymmetric lamina', 'deformed lamina', 'vertically stripped lamina' and 'fan 
shape plant'. The second cluster contained 'spear shape lamina', 'half variegated lamina', 'dwarf plant' and 'giant plant' variants. The variants 'weak plant' and 'long petiole' were aligned between the first and the second cluster (Figure 3). The third cluster consisted of 'leathery lamina' and 'malformed plant' variants, while the fourth cluster contained 'variegated plant', 'reddish plant', 'default lamina' and 'blackened pseudo stem' variants. The fifth cluster included 'sprocket lamina' and 'shattered bunch' types and the last cluster contained 'elephant ear shape lamina' and 'vigor plant' variants. The variant 'pale green pseudo stem' was in the middle space between the fourth and the fifth cluster, while the 'erected leaf' variant was clustered separately from the sixth cluster (Figure 3).

Morphological Principle Coordinates Analysis:

According to the principle coordinate analysis (PCOORDA), the first three principle coordinates (PCs) represent $81.5 \%$ of the total variation $(58 \%$ for PC1, $14 \%$ for PC2 and $9.5 \%$ for PC3, Fig. (4) The variants were distributed based on the first PC with different degrees of variability, whereas the 'variegated plant', 'malformed plant' and 'leathery lamina' variants were distributed at very high level of the first PC. The following variants were aggregated near from the middle of PC1: 'sprocket lamina', 'erected leaf', 'pale green pseudo stem', 'weak plant', 'elephant ear shape lamina', 'blackened pseudo stem', 'default lamina', 'dwarf' plant 'reddish lamina' and 'long petiole'. At the second PC, there were no high differences among the variants in relation to their distribution at this level except for 'sprocket lamina' and 'giant plant' that was located at the most high level of that PC and the 'variegated plant' that was separated at the most low level of PC2 (Figure 4). At the third PC, there were high differences among the variants in relation to their distribution at this level. 'Pale green pseudo stem' and 'erected leaf' variants were located at very low level of the PC3, while 'sprocket lamina', 'weak plant' and 'giant plant' variants were located at high level of the third PC (Figure 4).

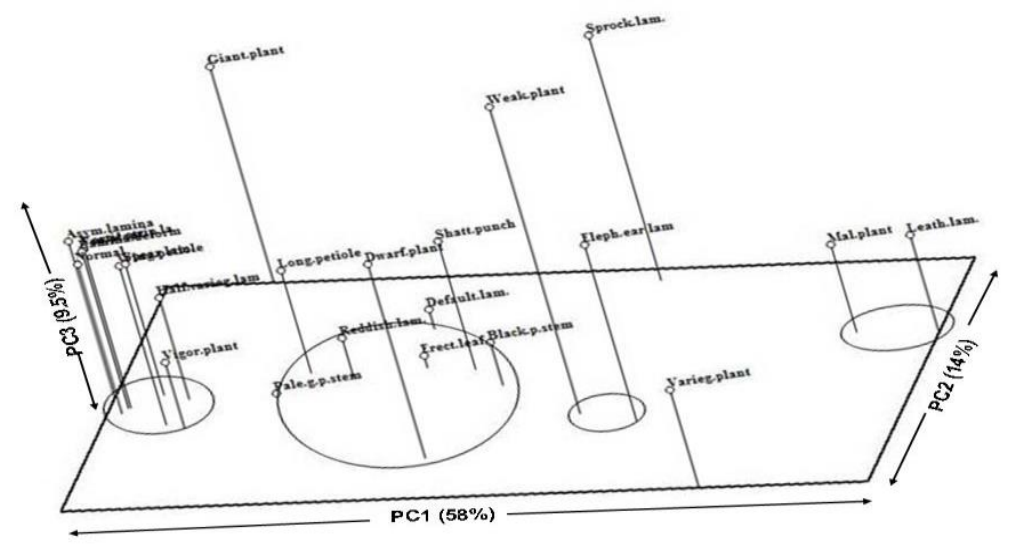

Figure (4): PCOORDA for banana cultivar 'Grand Nain' and twenty-three of its somaclonal variants based on morphological parameters. 
Most of variants aggregated together in the different PCs, this may indicated that most variants might reflect epigenetic changes, which happened during in vitro culture this point of view was in agreement with Larkin and Scowcroft, (1981). They reported that somaclonal variation could be defined as genetic variability generated during in vitro culture. On the other hand, Shailesh et al., (2010) stated that the composite data indicated that such off types were somaclonal variation and were not the result of epigenetic factor(s).

In our study, the variants 'variegated plant', 'pale green pseudo stem' and 'vigor plant' were genetically different from the normal plant according to the PCOORDA analysis which may suggested that, their changes are not epigenetic. The same results could be obtained from both morphological and molecular markers. Concerning the reasons of somaclonal variation, Damasco et al., (1998) strongly indicated that adventitious shoot multiplication is the main factor contributing to the formation of 'dwarf' offtypes. Adventitious buds were promoted by high concentrations of benzyl amino purine [benzyl adenine], by splitting propagules longitudinally during micropropagation and by preferentially selecting bulbil-like structures as propagules for further multiplication. The inherent instability of the cultivar being micropropagated was another major factor influencing the production of 'dwarf' off-types. Oh et al., (2007) reported that the molecular basis of somaclonal variation is not precisely known, but both genetic and epigenetic mechanisms have been proposed. The available evidence points toward the existence of labile portions of the genome that can be modulated when the cells undergo the stress of tissue culture.

The early diagnosis of somaclonal variation has been tested using DNA markers whereas James et al., (2007) presented that the source of this variation may derive from variation pre-existing in the mother plant or it may be induced in vitro. Many factors are known to influence in vitro induced variation, however, it has been proposed that hypo- or hypermethylation of DNA, which may trigger genome-wide changes, may be the underlying cause.

It can be concluded that the banana cultivar 'Grand Naine' was more related to 'winged leaf' variant, and both of them were related to 'leathery lamina' variant. It can be noted also that 'blackened pseudo stem' variant was related to the 'giant plant' variant. Most of variants aggregated together in the different PCs, this may indicated that most variants may reflect epigenetic changes which happened during in vitro and other may reflect real genetic variation. The variants 'variegated plant', 'pale green pseudo stem' and 'vigor plant' genetically different from the normal plant according to the PCOORDA analysis which may suggested that, their change are not epigenetic. Also, the obtained results from both molecular and morphological analyses were so far in contiguous with better resolution when using the PCOORDA analysis than cluster analysis. 


\section{REFERENCES}

Anderson J. A.; Sorrels M.E. and Tanksley S. D. (1993). RFLP analysis of genomic regions associated to preharvest sprouting in wheat. Crop Sci, 33: 453-459.

Creste, S.; Tulmann, N. A.; Silva, S.d.O. and Figueira, A. (2003) Genetic characterization of banana cultivars (Musa spp.) from Brazil using microsatellite markers. Euphytica,132 (3): 259-268.

Damasco, O.; Smith, M.; Adkins, S.; Hetherington, S. and Godwin, I. (1998). Identification and characterisation of dwarf off-types from micropropagated Cavendish bananas. Acta-Horticulturae. 490: 79-84.

Food and Agricultural Organization. Statistics 2009. www.fao.org.

Fernandez, A.; Corona, B.; Leon, O.; Cabrera, O. and Diaz, M. (1996). Characterization of variants and mutants from Musa spp. by polymerase chain reaction with arbitrary primers. Revista de Proteccion Vegetal, 11(3): 179-182.

Hegazy, A. E.; Aboshama, H. M.; Emara. H. A. and El-Shahed, A. A. (2010). Biotechnological studies on banana plant 1- Screening of vitroplants somaclonal Variation. 28th International Horticultural congress. Lisbon, Portugal; 22-27 August, p. 63.

Jaccard P. (1908). Nouvelles recherches sur la distribution florale. Bull. Soc. Vaudoise Sci. Nat. 44: 223-270.

James, A.; Peraza-Echeverria, S.; Peraza-Echeverria, L. and HerreraValenci,V. (2007). Variation in micropropagated plants. ActaHorticulturae, 748: 55-63.

Lagoda, P. J.; Noyer, J. L.; Dambier, D.; Baurens, F. C. and Lanaud, C. (1995). Abundance and distribution of simple sequence repeats in the Musaceae family. Microsatellite markers to map the banana genome. Induced mutations and molecular techniques for crop improvement. Proceedings, Vienna, Austria. 19-23 June, 287-295.

Larkin, P. J. and Scowcroft, W. R. (1981). Somaclonal variation a novel source of genetic variability from cell cultures for improvement. Theor. Appl. Genet, 60: 197-214.

Lu Y.; X. Zhang, J. Pu; Y. Qi and Y. Xie (2011). Molecular assessment of genetic identity and genetic stability in banana cultivars (Musa spp.) from China using ISSR markers AJCS 5(1):25-31.

Oh, T. J.; Cullis, M. A.; Kunert, K.; Engelborghs, I.; Swennen, R. and Cullis, C. A. (2007). Genomic changes associated with somaclonal variation in banana (Musa spp.). Physiologia Plantarum, 129 (4): 766-774.

Pancholi, N.; Wetten, A. and Caligari, P. (1996). Stability of meristem culture in context with somaclonal variation: a case study with banana. Journal of Applied Horticulture Navsari, 2(1/2): 72-81. 
Rajamanickam, C. and Rajmohan, K. (2007). Genetic divergence analysis of Nendran (AAB) ecotypes of banana (Musa spp.) using RAPD marker and morphological traits Recent trends in horticultural biotechnology, Vol-II-ICAR-National Symposium on Biotechnological Interventions for Improvement of Horticultural Crops: Issues and Strategies, Vellanikkara, Kerala, India, 10-12 January, 537-544.

Rohlf, F. J. (1998). NTSYSpc. Numerical taxonomy and multivariate analysis system, version 2.02c. Exeter Software, New York.

Roux, N.; Strosse, H.; Toloza, A.; Panis, B. and Dolezel, J. (2004). Detecting ploidy level instability of banana embryogenic cell suspension cultures by flow cytometry. Banana improvement: cellular molecular biology, and induced mutations. Proceedings of a meeting held in Leuven, Belgium, 24-28 September, 251-261.

Saghai-Maroof M. A., Soliman K. M., Jorgensen R. A. and Allard R. W. 1984. Ribosomal DNA spacer length polymorphism in barley. Mendelian inheritance, chromosomal location and population dynamics. Proc. Nat. Sci,. 81: 8014-8018.

Saifullah, K.; Bushra, S.and Naheed, K. (2011). Establishment of genetic fidelity in vitro raised banana plantlets. Pakistan Journal of Botany, 43(1): 233-242.

Shailesh, V.; Anil, P. and Kothari, R. M. (2010). Phenotypic characters of various off types identified in laboratory, primary and secondary hardening in tissue cultured banana var. Grand Naine. Indian Journal of Biotechnology, 9 (2): 178-186.

Zaffari, G. R. and Kerbauy, G. B. (2010). Somaclonal variation analysis in micropropagated plants of Musa acuminate cultivar Grande Naine using RAPD marker. Agropecuaria Catarinense, 23(1): 76-80. 


$$
\text { دراسات بيوتكنولوجيه على نبات الموز: }
$$

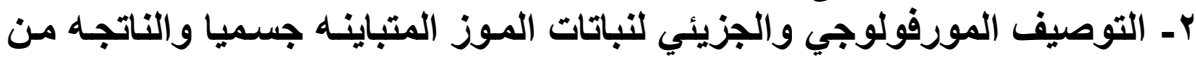
زراعه الانسجه صنف جرندان

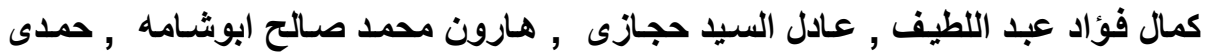

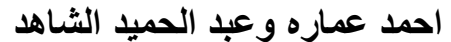
جامعه المنوفيه ـ معهد الهندسه الوراثيه والتكنولوجيا الحيويه ـ قسم البيوتكنولوجيا النباتيه

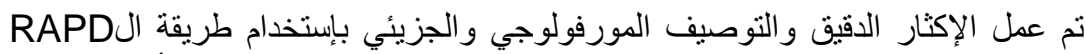

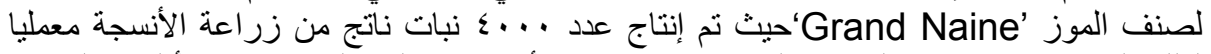

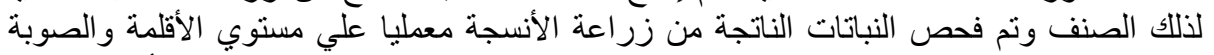

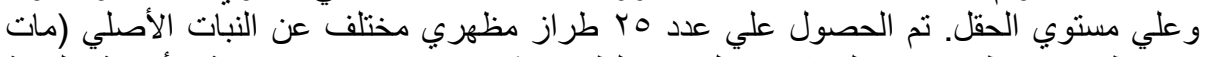

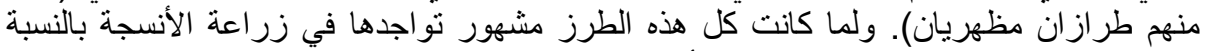

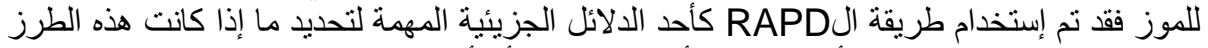

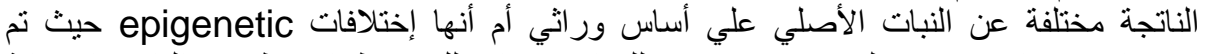

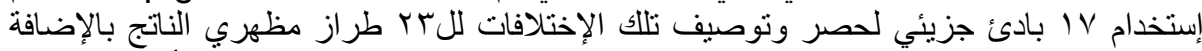

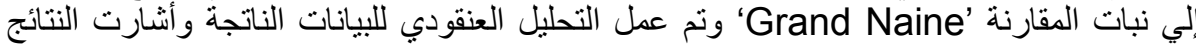

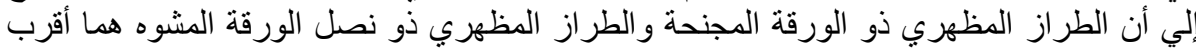

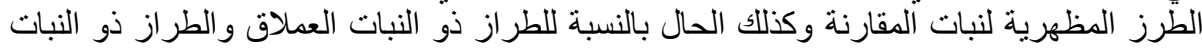

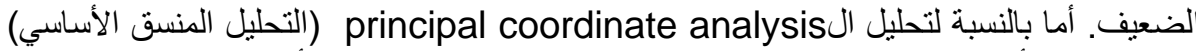

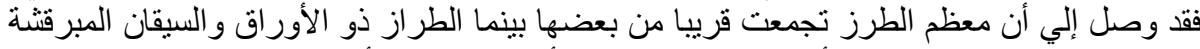

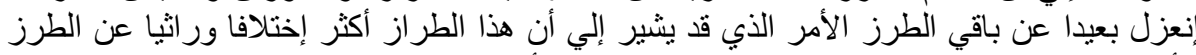

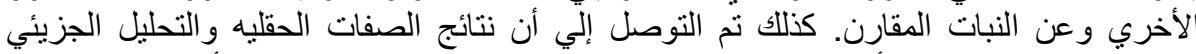

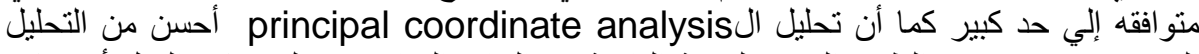

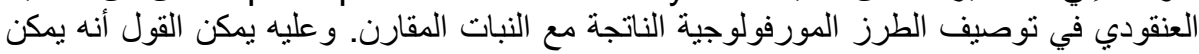

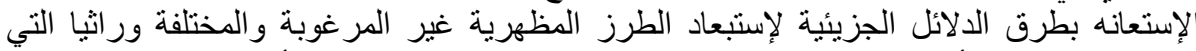
تظهر من زراعة الأنسجة قبل زراعتها في الحقل لتوفير نكاليف الزراعة الطية والأقلمة.

كلية الزراعة - جامعة المنصورة كلية الزراعة - جامعة المنوفية
قام بتحكيم البحث

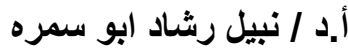
أ.د / ابر / نبيم رثئم ابو المقصود ابراهيم 
J. Plant Production, Mansoura Univ., Vol. 2 (11), November, 2011 
Table 3: Similarity coefficient correlation among banana cultivar Grand Nain and its somaclones depends upon data generated by RAPD markers.

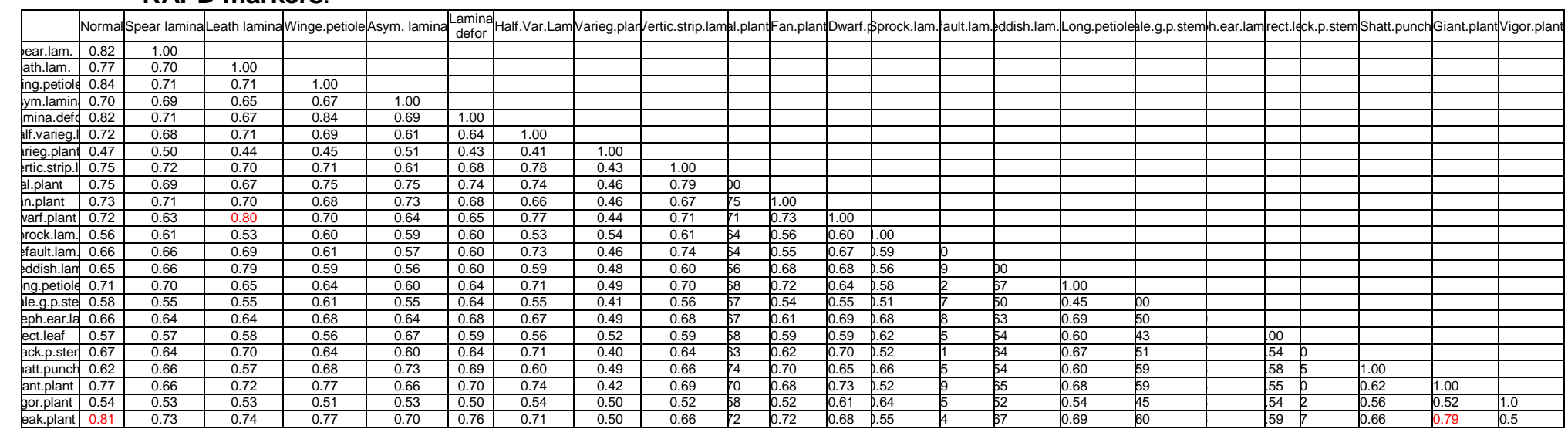

